\title{
Professionalisation of Operating Department Practice: An
}

evolutionary perspective

Rob Corbett ${ }^{\mathrm{a} *}$ and Steve Suckling ${ }^{\mathrm{b}}$

${ }^{a}$ School of Health \& Social Care, Staffordshire University, Stafford, United Kingdom;

${ }^{b}$ Visiting Fellow, Staffordshire University, Stafford, United Kingdom

*School of Health \& Social Care, Staffordshire University, Blackheath Lane, Stafford,

ST180YG.r.p.corbett@staffs.ac.uk 


\section{Professionalisation of Operating Department Practice: An evolutionary perspective}

The health care professionals staffing the operating theatres of UK hospitals are pursuing a professionalisation agenda based around increasing the academic level of the credential required for entry to their professional register. This paper explores the impact of this on registered Operating Department Practitioners (ODPs) and Theatre Nurses by proposing a theory of professionalisation based on the work of evolutionary biologist Leigh van Valen (1973). Selected findings from a wider study of human capital development in the operating theatre are presented which demonstrate an inter- and intra-professional evolutionary process which resonates with van Valen's Red Queen's Hypothesis. The findings show how registered professionals carry out a benchmarking exercise to determine the most suitable route of professional development. The ODPs and nurses who decide to participate in credentialised continuing professional development do so to remain competitive with the new breed of graduates entering the profession. However, their continued study only serves to bring them to the level of the new breed professionals; they are running fast to stand still. We explore and comment on the ripple of behaviours the rise in academic credential produces.

Keywords: benchmarking, professionalisation, Red Queen's Hypothesis, Operating Department Practice

Subject classification codes: include these here if the journal requires them

\section{Introduction}

When a perceived predator enters a system, the system responds and reorganizes. (Freedman, 2015). Some parts of the system will be consumed by the predator; other parts will struggle hard to maintain their status quo; still other parts will assume the characteristics of the predator itself, competing for dominance and driving even further changes. 
As the academic level of professional entry credentials for healthcare professions rise, the employment of graduates is causing the existing system to respond and reorganize. One of the responses can be described in the terms of an evolutionary shift, where the non-graduate workforce improves their academic credentials to place themselves on an equal academic footing, thereby maintaining their competitiveness for career progression. The paradox for this system is that it becomes harder to stay the same. This struggle as a system response is characterized by the Red Queen, the Lewis Carrol character, who appears in Alice Through the Looking Glass as explained by Easton $(2007 ; 171)$ :

... the Red Queen interrupts the conversation to grab Alice by the hand and start running at breakneck pace. After some minutes of sprinting, Alice notes with wonder that they are still in the same spot. Nothing unusual, the Red Queen remarks dryly; in her country 'it takes all the running you can do to keep in the same place'.

This paper explores this paradox through the Red Queen's hypothesis, presenting a theory that educational credentials create a predatory response in the healthcare system, causing some individuals within it to work increasingly harder to maintain their current position in the workforce.

The findings presented in this paper are taken from a wider investigation into the impact of graduate entry from organisational, professional and individual registrant perspectives (Corbett 2017) which originally drew on a combination of Becker's (1993) Human Capital Theory and Larson's (1977) model of professionalisation as theoretical frameworks. A subset of this data is used to demonstrate how the Red Queen's hypothesis can be applied to enhance existing theories of professionalisation, and improve our understanding of frontline workforce decision making. 


\section{Context of the Study}

The initial, pre-registration training of health care professionals in the United Kingdom (UK) is in a transformative period. The move from hospital based Training Schools to Higher Education can be linked to an ongoing professionalisation agenda with a concomitant expectation that the academic entry requirement to access the health professions moves to graduate level (Debel \& Branson, 2009).

This educational change is impacting on the professional groups staffing the operating departments of UK hospitals, where the registrant workforce is drawn from two professional groups: Operating Department Practitioners (ODPs) and Theatre Nurses. The nursing profession has completed the transition to graduate entry based on the rhetoric of possession of higher level qualifications leading to a workforce that are better able to provide high quality patient care (Department of Health 2008; Aiken et al., 2003). For the ODP profession the move to graduate entry remains aspirational, despite several Universities across the United Kingdom offering a degree level version of the course.

Nurses traditionally staffed the operating department, but a failure to recruit theatre nurses in sufficient numbers in the 1960s led to a review into the staffing and organisation of operating theatres (Reid \& Catchpole, 2011). A key recommendation of the Lewin Report of 1970 was the introduction of a new, specialised role, with a formalised educational pathway for their development (Reid \& Catchpole, 2011). This role was the forerunner of today's ODPs.

Since the Lewin Report, operating departments have been recruiting their workforce from both ODP and Nursing professions. However, this has not been without its difficulties as reported by Timmons and Tanner (2004). The main issue of discontent 
resulted from the employment of two groups of workers performing similar roles, and the dominance of the established nursing profession over the fledgling ODP profession. Nursing dominance in the operating department remained until 2004 due to their state registered status (Reid \& Catchpole, 2011). The statutory registration of ODPs in 2004 placed them in a position of professional parity with their nursing counterparts, and the introduction of a common pay spine resulting from the Department of Health's Agenda for Change initiative (Department of Health, 2004) further eroded professional boundaries.

Both professional groups are prepared for their role through completion of specialist training programmes hosted by higher education institutions. In the authors' host institution, Nurses study for a BSc(Hons) in Nursing and ODPs for a Diploma(HE) in Operating Department Practice (although the academic level of training for ODPs is now under review and may increase to degree level). The result of this is that ODPs receive a specialist training focused on their work in the operating department and nurses a specialist programme of study that may, or may not, include a period of clinical experience in the operating department.

The lack of empirical research on the operating theatre workforce, and the nature of recruitment of a registrant workforce from two separate professions provides a fertile area on which to base this paper. At the macro level of the profession, the changes in the current system appear to place nurses in a predatory position as the higher academic level for entry to their profession perpetuates their dominance over ODPs. Arguably, graduate nurses are better equipped for career progression in a field where, increasingly, academic credentials are used as a screening tool to indicate the individual's suitability for promotion. 
ODPs, on the other hand, are responding by lobbying their regulatory body for review of the academic level of the credential for entry to the professional register. As the disparity in academic credential provides a threat to the survival of the ODP profession, several higher education institutions have taken the decision to validate ODP programmes at degree level ${ }^{1}$.

There is also threat within the professions, at the micro level of the individual. The introduction of graduate entry to nursing and the validation of ODP programmes of study at degree level are recent phenomena. There are many registered nurses and ODPs who do not hold the degree level professional credential potentially placing them at a disadvantage in relation to the new-breed graduate entrants to the professional register.

\section{Professionalisation and the Red Queen's Hypothesis}

The published literature on the operating theatre workforce focuses primarily on the interprofessional tensions between ODPs and nurses (Timmons \& Tanner, 2004), and the discontentment of ODPs with the professionalisation process which, according to Timmons (2011), amounts to nothing more than regulation. Graduate entry to the nursing profession has led to a professional discourse in ODP relating to their academic entry level (College of Operating Department Practitioners, 2011a) which indicates coevolutionary tensions like those faced by organisations when their competitors increase productivity (Freedman, 2013).

${ }^{1}$ The HCPC register of approved training programmes (http://www.hcpcuk.org/education/programmes/register/index.asp?intStartRow=21\&EducationProviderID=all $\&$ StudyLevel=all\&ProfessionID $=7 \&$ PostRegistrationID $=\&$ ModeOfStudyID=all \&IntakeStat us $=$ Open\&RegionID=\#educationSearchResults) shows that 24 higher education institutions deliver pre-registration ODP training. Of these, nine provide a BSc course, nine a diploma course, and six provide both BSc and diploma courses. 
When an organisation increases productivity, a period or learning and development follows where competitor organisations either increase their productivity or lose business. The Red Queen's Hypothesis, developed by evolutionary biologist Leigh van Valen (1973), has been used to explain organisational response to the predatory instincts of its competitors (Barnett and Hansen 1996). The hypothesis posits the co-evolution of species in terms of their ability to adapt to their current environment and survive. In van Valen's (1973) theory, change in a system produces one of two effects: evolution, where a species develops new characteristics to suit their changing environment; or maladaptation, where the species ultimately becomes extinct.

Application of the Red Queen's Hypothesis to the co-evolution of ODPs and nurses in the operating department, suggests that any development in professional status in one group, will be followed by a similar development in the other. At the level of the profession this is clearly evident. The entry level credential for access to the nursing professional has been raised to degree (Nursing \& Midwifery Council, 2010). The entry level credential for ODP remains at higher education diploma (Health and Care Professions Council, 2017), even though the College of Operating Department Practitioners (2011b; the professional body for ODPs) launched their degree level curriculum in April 2011. In this evolutionary milieu, the determinant of dominance shifts the focus to professional power which, in turn, is signified by academic screening.

\section{Academic credentials as an indicator of professional dominance}

Review of the extant literature surrounding the increase in the academic level of professional entry credential links directly with Larsons's (1977) model of professional development. Due to the dearth of literature relating to the operating department and Operating Department Practitioners, research evidence from other health care 
professions, in particular nursing (the closest profession to ODP in the context of this paper), was explored to chart their evolutionary progression from vocation to academe.

The move to graduate entry nursing is based on the work of Aiken et al. (2003) who contend that graduate nurses provide more effective care than their non-graduate counterparts. In their comparison of graduate and non-graduate nurses' performance in the United States, Aiken et al. claim a significant positive correlation between patient mortality and the academic level of the professional credential held by the nurse. They report that the graduate nurses in their study were better equipped to identify patient deterioration at a much earlier point than non-graduates and thereby implement the necessary care intervention to reduce the risk of further deterioration to the point where the patient's condition reaches emergency status. However, their failure to isolate essential confounding variables brings this finding into question.

For example, the experience of the nurse is not considered to play any part in their ability to identify patient deterioration. It is also unclear whether any nurses in their study had nursing experience at non-graduate level before progressing to the degree level nursing credential. What Aiken et al. (2003) do demonstrate is that that a higher ratio of nurses per patient allows nurses more time to spend with each individual patient, which allows the nurse to make a thorough review of the patient's condition.

This second finding from the Aiken et al. (2003) study is reflected in an analysis of the impact of skills on productivity produced by Keep, Mayhew and Payne (2006). In this review, Keep, Mayhew and Payne report on the growth in the number of training courses available in the United Kingdom, particularly within higher education, and their negligible impact on workforce productivity. One of their findings is that workforce practices have failed to change and redesign in response to the higher skilled workforce, despite the rhetoric of new ways of working. Merely holding a professional 
qualification at degree level is not an indicator of better workforce performance.

However, investment in the workforce to provide adequate numbers of appropriately qualified staff may contribute to improved service delivery.

Despite the limitations of the Aiken et al. study the introduction of graduate entry nursing in 2010 came as a direct result of this work and was surrounded by claims of improved quality of care based on the skills and knowledge displayed by graduate nurses as the two quotations below illustrate:

... a shift to the concept of quality of care has led to a breakthrough in our ability to measure and to link nurse practice to patient outcome. And quality of care is a key argument behind the current determination to move to a graduate workforce. (Debell and Branson, 2009, p554, emphasis original).

The NMC and many others believe that nurses educated to degree level will be able to provide better care (Nursing and Midwifery Council, 2010, p6).

The inference drawn from this is that there is a link between increasing the academic level of entry to the nursing profession improves their levels of productivity in terms of the effectiveness of their patient care.

This resonates with Larson's (1977) model of professionalisation. In her thesis, Larson focuses on how the medical profession developed from disparate groups of barbers and physicians to the strongly coherent professional group of today. Professionalisation is presented at a linear process which is summarised in figure 1 below:

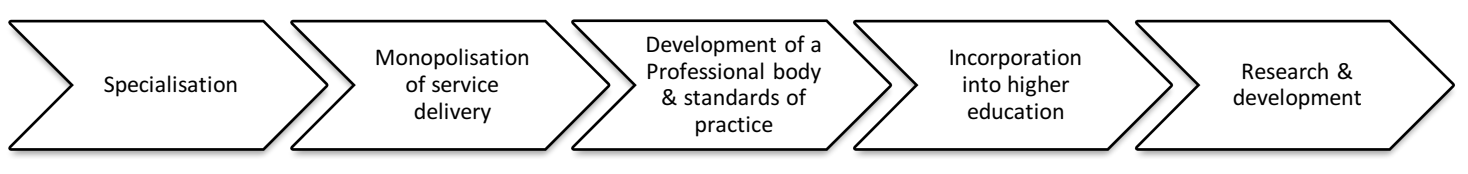

Figure 1: Professionalisation as a linear process based on Larson (1977) 
Specialisation and productivity are increasingly important in the National Health Service (NHS) which is evolving to meet the demands of a changing health demographic. An aging population, living with a range of co-morbidities (NHS England, 2014) presents challenges to health care professionals when in-hospital care is required. This, coupled with the rate of technological advancement in diagnostics and treatments, means that the level of knowledge health care professionals require to carry out their role is expanding.

The move from generalist to specialist health care practitioners has a further impact on the health professions. Nancarrow and Borthwick (2005) provide the example of the specialisation of orthopaedic surgery, which resonates with the operating theatre workforce. As surgeons focus on the specialised, surgical elements of their orthopaedic surgery, their scope of practice contracts. This leaves lower-order aspects of treatment and care which then become incorporated into the job descriptions of the professions allied to medicine. In this example, Nancarrow and Borthwick describe how physiotherapists have taken on responsibility for the rehabilitation of patients with skeletomuscular injury, and how podiatrists now perform minor surgery in their delivery of foot care.

The examples above demonstrate how specialisation and contraction of one role results in the expansion of another, and this is evident across healthcare with the development of specialist practitioners. In the operating department, jobs are evolving to include that of the Surgical First Assistant, Surgical Care Practitioner and Physicians' Assistant (Anaesthesia). Each of these involves the allied health professional (in this case the ODP) or nurse expanding their scope of professional practice to take on duties that were once performed by medical practitioners. This in turn, leaves the perceived lower-order duties of the allied health professional to be taken up by support workers, 
who then extend their role of practice. Thus, workforce specialisation and professionalisation is determined by which workforce group moves in to expand their role.

However, there are difficulties in the operating department where two workforce groups are vying for the same roles and, yet, neither has monopolised service delivery. As alluded to earlier in this paper, both ODPs and nurses are now distinct professional groups with their own right, where standards of practice are developed and monitored by professional and regulatory bodies.

Both professions are sited in higher education but there is debate as to whether nursing and the allied health professions should be considered as true professions due to their lack of a profession-specific body of knowledge (e.g. Yam, 2004). However, as the medical role has continued to specialise and contract as a result of their continued specialisation, nurses and allied health professionals are expanding their scope of practice in essential aspects of patient care (for example monitoring the patient's condition and identifying and responding to signs of deterioration). As such, these professions are developing a hybridised body of knowledge which is being added to as these professions establish themselves in higher education.

The expansion of job definitions and increase in the academic level of the qualifications of entry to the health professions follows Canibano and Potts's (2016) job-centred view of knowledge and supports the axioms:

Axiom 1: jobs are carriers of knowledge;

Axiom 2: jobs are structures of knowledge, the associations between the rules the agent [ODP or nurse] carries and those of other agents [medical practitioner, employing organisation, professional body] determines the capabilities the job has; Axiom 3: jobs are processes of knowledge, becoming more or less complex through time (Canibano and Potts, 2016; 7). 
NHS England (2014), professional bodies and regulatory bodies view the key indicator of the challenges faced by modern health care delivery as the academic credential attributed to entry to the profession. The overarching message from Canibano and Potts is that as jobs evolve, the knowledge required to do them evolves. This has a knock-on effect to the workforce who must also evolve along with their job. In a multi-professional workplace, competitive tensions arise until such a point in time when either one group assumes monopoly of service provision, or the two groups evolve into a hybridised workforce.

Taking this evolutionary perspective to professionalisation provides the ideal opportunity to explore the development of two professional groups, co-existing in one specialist area of health care.

\section{Research Design}

To explore the impact of the increased academic entry level to nursing on the nursing and ODP professions, a mixed-methods research design was developed based on data collected via questionnaire and semi-structured interview. Mixing methods provided a naturalistic approach to the investigation (Tashakkori and Teddlie, 2010), where the research design is driven by the research questions (Bryman, 2007). Removal of the constraints placed on the research by the rigidity of research paradigms and the associated incommensurability thesis (Gorard, 2010) facilitates exploration of objective, subjective and intersubjective events concurrently in the generation of new knowledge (Johnson and Gray, 2010). Furthermore, the mixed-methods design allowed for the triangulation of data which strengthened the internal validity of the study (Torrance, 2012). 
Ethical approval was granted by the authors' host institution's research ethics committee. As the research sample comprised staff employed in the NHS, the Do I Need NHS REC decision tool ${ }^{2}$ was also completed which confirmed that ethical approval from the author's host institution would be sufficient. A purposive sample of ODPs and theatre nurses participated in two strands of data collection as detailed below.

A questionnaire was used to generate data in the first strand of the project. 150 questionnaires were distributed to qualified ODPs and theatre nurses, of which 60 were returned representing a completion rate of $40 \%$. Of these, 38 questionnaires were completed by ODPs and 22 by theatre nurses. The questionnaire was divided into three sections: the first collected data about the respondents' role, salary and years of service; the second part generated data relating to their participation in continuing professional development activities leading to a formal academic qualification; the third part explored the respondents' attitudes towards degree level entry to the ODP and nursing professions.

This was followed by semi-structured interviews with a stratified sample of 11 qualified ODPs and theatre nurses, some of whom may have completed the questionnaire. This sample was stratified by salary banding. In the NHS, salaries are based on a banding system, where newly qualified ODPs and theatre nurses enter on pay Band 5. Higher pay Bands are ascribed to more senior roles and, in this study, ODPs and theatre nurses occupying roles on pay Bands 5, 6, 7 and 8 were included. One ODP and one nurse from each pay band was included in this sample and a decision was

\footnotetext{
${ }^{2}$ Note: the NHS process for ethical approval via the Health Research Agency were amended from 31" March 2016 and this decision tool no longer forms part of the ethical review process. See http://www.hra.nhs.uk/research for further details.
} 
made to include three additional interviewees on pay Band 6 (two ODPs and one nurse) from a newly formed Theatre Practice Development Team.

Data from the questionnaire strand were analysed using descriptive statistics as the purpose of this data was to identify trends and relationships between academic qualifications, salary, professional group and scope of practice. Responses to open questions underwent thematic analysis. Data from the interview strand were transcribed verbatim and initially coded based on the areas covered by the primary research questions. The data were reviewed iteratively and the codes refined to develop the theoretical themes presented in this paper.

\section{Analysis and Discussion}

The data presented in this paper focus on a sub-group of the main sample who are either currently engaged in credentialised continuing professional development (CPD) activities, or plan to engage with credentialised CPD activities in the next 12 months. This group was identified through a set of specific questionnaire questions (figure 1).

Figure 1: Engagement in formal credentialised CPD activity (i) since qualification and (ii) planned in next 12 months.

\begin{tabular}{c|ccc|ccc}
\hline \multirow{2}{*}{ Profession } & \multicolumn{2}{|c|}{$\begin{array}{c}\text { (i) Have participated in CPD since } \\
\text { qualification }\end{array}$} & \multicolumn{2}{|c|}{ (ii) Planned participation in next 12 } \\
months
\end{tabular}

Credentialised CPD activities are defined, for the purpose of this study, as those activities that lead to a formal academic award, and those ODPs and nurses that 
answered yes to either question (i) or (ii) in figure 1 were asked to complete filter questions regarding the level and type of engagement (figures $2 a-2 c$ ).

Figure 2a: Academic level of study of nurses and ODPs currently engaged in credentialised CPD activity

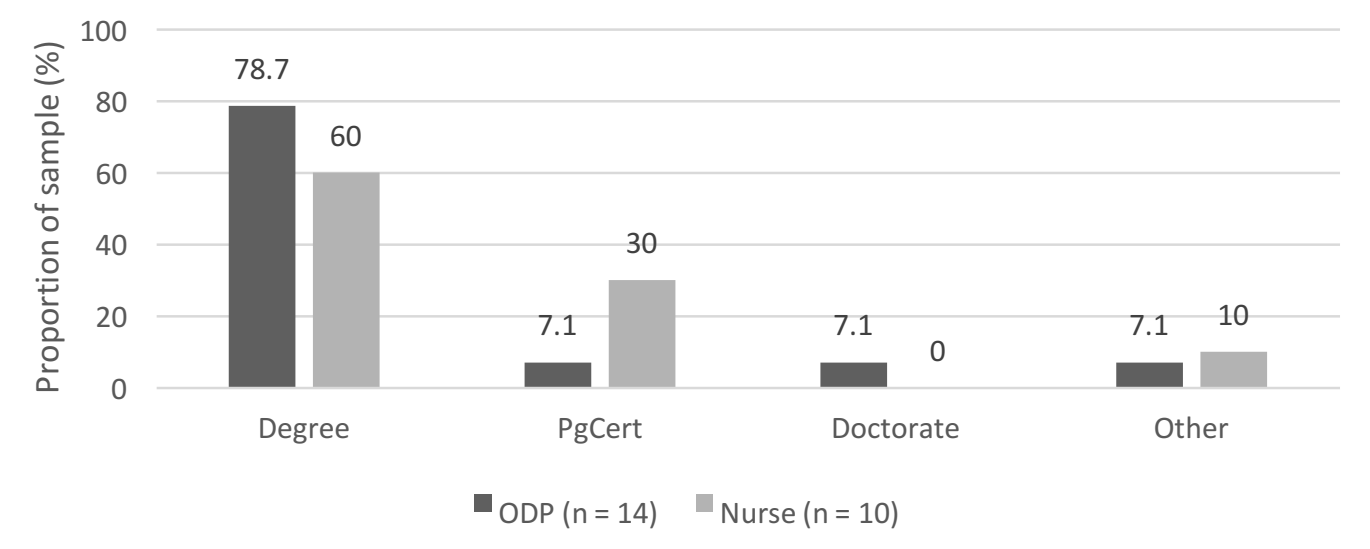

Figure 2b: Proposed academic level of study of nurses and ODPs planning to engage in credentialised CPD activity in the next 12 months

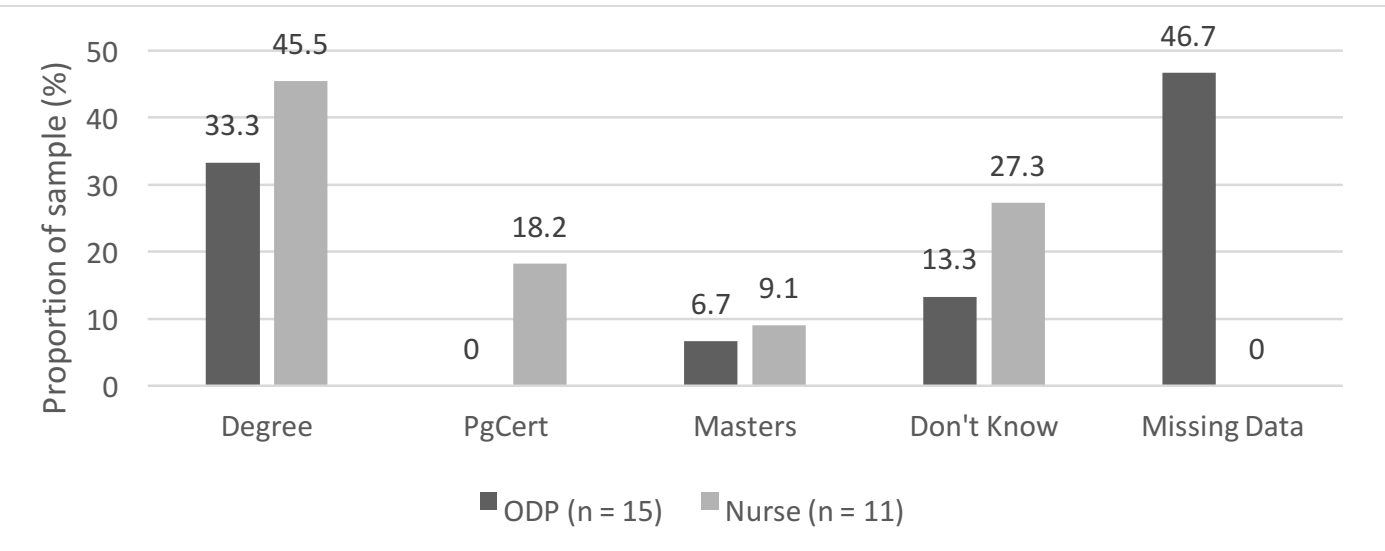


Figure 2c: Proposed type of engagement with higher education for those planning credentialised CPD activity within the next 12 months

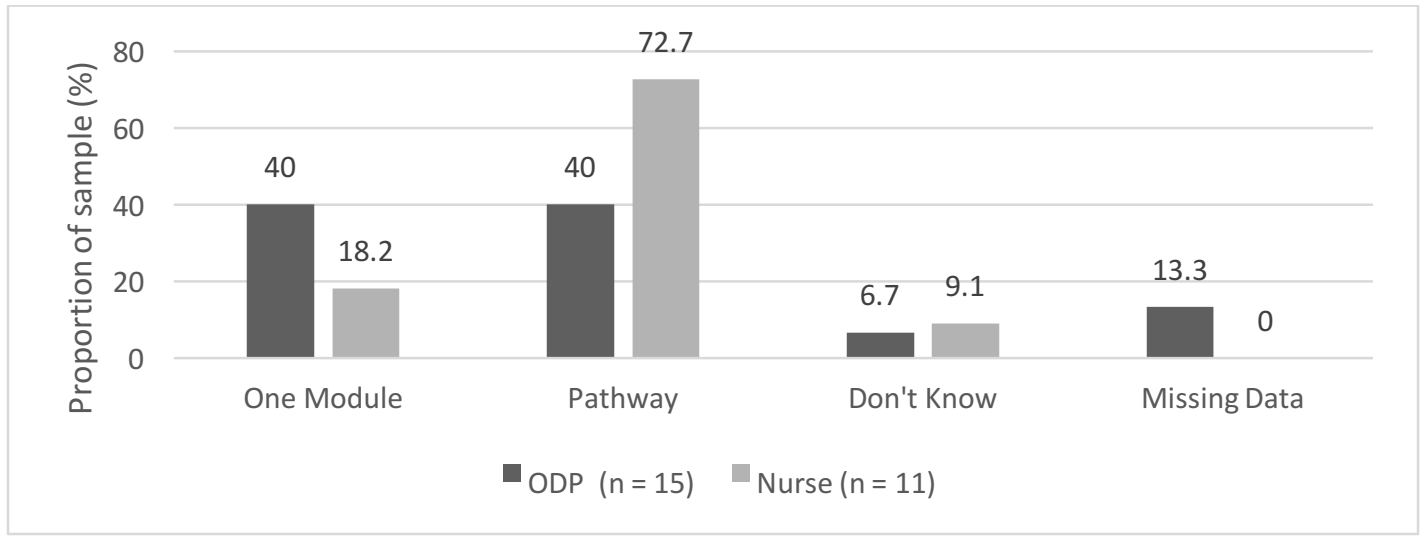

The data presented in figure $2 \mathrm{a}$ demonstrates that most nurses $(60 \%)$ and ODPs $(78.7 \%)$ in this sample are currently engaged in credentialised CPD at degree level. As the profession moves forward and increases the academic credential required for entry to the group, existing members of the profession appear to be driven to improve their academic credentials to the same academic level as that of the new entrants (i.e. degree level for nursing). Although, at the time of writing, the entry level to the ODP profession remained at Diploma level in the area in which this study was conducted, the number of ODPs completing degree level study could be because of inter-professional competition. It is possible that the ODPs are competing with Theatre Nurses for their professional survival in the operating department using the academic credential as a signalling mechanism for employers, rather than their clinical prowess.

Some practitioners extend their academic credentials beyond the professional entry level (figure 2a) by participating in Postgraduate Certificate and Master's level study. A substantially larger proportion of the nursing cohort (30\%) is engaged with post-graduate level study than their ODP $(14.2 \%)$ counterparts and this may be a result of longer association of nursing with higher education. The ODPs and nurses selecting the 'other' option to the questionnaire question indicated that they were currently engaged with a stand-alone mentoring module, which is at degree level. At present, the 
mentoring module carries significance for registered practitioners as it serves as one of the employers' screening credentials for promotion from pay Band 5 to pay Band 6 .

A similar picture is presented for those planning to engage in credentialised CPD in the next 12 months (figures $2 \mathrm{~b}$ and 2c). Most ODPs (33.3\%) and nurses (45.4\%) plan to study at degree level, and a larger proportion of the nursing sample $(27.3 \%$ aggregated PgCert and Master's proportions) plan to extend their credentialised study to post-graduate level as compared with their ODP counterparts. Of these most nurses (72.7\%) and $40 \%$ of the ODP sample will enrol to a full pathway (figure 2c).

It is evident from this limited data set that the participants in this study have a desire to complete a credentialised qualification to top up the academic level of their professional award. It also shows a mixed approach to this study with some professionals choosing to enrol onto a complete programme of study, with others targeting a specific degree-level module to signify their ability to study at degree level.

The drivers for participation in credentialised CPD activities were explored through the inclusion of open questions in the questionnaire where respondents were asked to give their views on the impact of the introduction of graduate entry in nursing on their role in the operating department. The following extracts were typical of the responses for both ODP and nursing professions:

So far the changes to diploma/degree has not affected my role. But promotion may become an issue due to essential criteria on applications for higher banded positions (Band 6 Nurse);

Think we will be required to all attain the same academic standard or professional future opportunities will not be fair to all (Band 6 ODP);

Impact will be minimal on myself, but as a Band 6 I may feel under pressure to up my qualification from diploma to degree (Band 6 ODP). 
The questionnaire participants cited above confirm that academic credentials are being used as a screening tool for promotion and that this will generate competition between members of the workforce, where those with lower-level academic awards are required to improve their academic credentials or lose out on promotion. However, this phenomenon is evidenced in both ODP and nursing professions, as nurses with a lower academic entry level are also looking to compete with the new graduate entrants.

These findings were complemented by data from the interviews. The first extract presented is from the interview with a Theatre Nurse on pay Band 6. During the interview, it was established that this Nurse held the diploma level nursing qualification on entry to the profession and then completed a degree post-qualification. When asked the reason for completing the degree, they were very clear:

Career progression. To get the same qualification as some of my peers had already got. Because not long after I qualified they changed the nursing training so that it went to a full degree programme. They took the diploma away completely so some of the students that were coming through had more [pauses] were more highly qualified than I was. And I felt that to be on the same level as them I needed to up my game and increase my level of competition.

Possession of a degree appeared to benefit this nurse:

When I'd completed my degree, some Band 6 posts came up and I applied, along with two or three other people, and even though I was the person with the least experience in recovery, I got the post because academically I'd built myself up into a more substantial position than some of that competition had.

This nurse had a clear idea of what was needed to be competitive when it came to promotion. In effect, they have benchmarked their current position against the newbreed graduate entrant nurses and have determined their academic development based on remaining competitive with graduate entrants. The increase in academic credential 
was used as an effective signalling tool to their employer and it is perceived that it is this, and not clinical experience, that led to this interviewee's promotion.

The interesting aspect of this passage of interview does not relate to whether the degree level credential was influential in their success, it is how the individual positioned themselves to be competitive. The Band 6 Nurse is carrying out a benchmarking activity to determine what they need to do to fit the requirements for promotion. This is also evident in the interview with a Band 7 Senior ODP:

The person specs [specifications] for the jobs had changed for a Band 7 role to say that you had to have a degree to [pauses]. So, my thought behind that was if I need to apply for a job, then I will need a degree.

The continuation of the Senior ODP's undergraduate studies through to degree level were also prompted by the need to remain competitive. However, the ODP is looking back from their position of seniority and benchmarking to ensure that they can maintain their competitiveness. Although the ODP seems to be employing the same strategy as the Band 6 Nurse, the differences in approach between them presents the opportunity to develop an alternative perspective based on their benchmarking activities. The nurse is clearly looking to the future and engaged in prospective benchmarking. Here the key question is 'what do I need to do to make myself competitive and improve my chances of promotion?' The Senior ODP is looking back and engaged in retrospective benchmarking. The key question here is 'what do I need to do to make myself competitive so that I can maintain my current position?'

These benchmarking processes resonate strongly with the processes used by organisations in their strategic planning processes where they measure their current performance against that of their competitors. However, in this case the job-centred view of knowledge and organisational growth presented by Cannibano and Potts (2016), 
is replaced by the academic level of qualifications as the key benchmark for the growth and development of the ODP and nurse cited above.

The interview with the Band 6 nurse went on to explore their plans for further academic study:

I've just done another diploma; I've got an advanced diploma in anaesthetics now. I did that because I've changed my role from recovery now. So I'd got to where I'd got in recovery and I've changed my role again to Practice Development Team. So my competition now is two ODPs and me within the same team. So again I've found myself in a position where my peers were more qualified in certain aspects of the role we now do than I was myself. So I needed to do something to up my knowledge and my skills to make myself level to where they are.

The nurse went on to say:

If somebody is coming through with more knowledge and skills than I've got, I'd [pauses] it's all competition isn't it? And in the role that I've got now, I'm supposed to be supporting people. So if I'm not as qualified as somebody that's coming through from the bottom then where do I stand in supporting them? I think competition is healthy. You've got to strive to gain new knowledge. You learn from each other all of the time. So if somebody is learning something new then we should be sharing it and we should be accessing the new things to make the best practice that we can deliver.

The interesting aspect of the quotations above relates to the perceived competitive nature of the workplace. As this nurse's work role develops, they encounter colleagues with differing qualifications which are viewed as a threat to work-placed survival. A newly promoted Band 6 diplomate nurse was interviewed and presented a similar picture:

I only got my Band 6 in March [had been in this post for 6 months at the time of interview] and obviously, when you apply, they're looking for people who have got degrees or have done mentorships or things like that. And since qualifying I 
haven't really had the opportunity to go and do any further study, but over the last few months I've thought 'I think I really [pauses] now I've gone up a Band I really need to pull my finger out and start'[to look into degree level study].

The nurses cited above are competitive and scan their environment to see where they sit in terms of their experiences and academic credential. The environmental scanning continues as the nurses enter their respective new roles where, immediately, new threats are identified. In both cases cited above, the nurses' benchmarking activities are aimed at keeping up with their competitors, which can be likened to the paradox running to stand still; their academic developments only take them to the point at which the new breed of registrants are entering the profession.

The Red Queen's hypothesis can be used to illustrate how professional groups may act like corporate organisations in their development; an advancement in one professional group results in other similar groups pursing the same development. This results in a coevolution of the professions which is the basis of van Valen's Red Queen's hypothesis (Easton, 2007). The data analysed in the current study can be used to take the Red Queen concept a stage further and apply this to an individual's professional development which is linked to the benchmarking phenomenon discussed above.

Theoretically, because of individuals improving their academic credential, the organisation should become more productive (Canibano \& Potts 2016). However, the paradigm-shift to credentialised professional entry appears to have created a situation in the current workforce where the new graduate practitioners are no more productive than those with older, lower-level awards. Some of the practitioners holding older awards feel that they must increase their academic credentials to remain competitive in terms of promotion opportunities, but others are happy to remain with their lower academic profile. This appears to be creating a position of stasis, where the professions are 
redefining their role, and entry to it based on the rhetoric surrounding the increasing academicisation of the preparation for professional practice.

What ultimately appears to be happening at present is the development of an academic hierarchy where those at the top, holding higher academic credentials are in a very good position to improve their career prospects. They are also better placed to make use of any available funding on offer for professional development to further increase their academic credential (e.g. from Bachelor degree to Master's) as they have the academic confidence and competence to do so. Those at the lower end of the hierarchy, holding the lower-level awards are theoretically always playing catch up; first to get to the professional entry level academic credential of the new breed, and then to pursue them through the postgraduate framework. The consequences of falling behind in terms of academic credential were made very clear by a Band 6 ODP Team Leader interviewee:

When we went through the Agenda for Change there were people who were very, very experienced, who were actually made redundant. And people with a degree were kept on. So that's my perception now. I think it's a bit dangerous. If they ever have another cull of staff, you've got to be up there with the rest of them.

This ODP is alluding to the process of maladaptation which is a consequence of failure to evolve (Easton, 2007). Agenda for Change was a process of regrading and redefining job descriptions in the NHS based on a common Knowledge and Skills Framework (Department of Health, 2004). It is this ODP's perception that this led to the culling of staff that did not hold the necessary level of academic credential. Based on this, the ODP is predicting a precarious future for those ODPs and nurses who do not engage in credentialised CPD activity. 
The ODP and theatre nurse comments are telling. The Red Queen's hypothesis illustrates well how the introduction of a new qualification standard activates a range of behaviours directed towards keeping pace with the new breed. If professional attainment creates a ripple of behaviours which result in professional staff working hard to simply to stand still, then policy to increase academic level of entry to the professions appears to be failing. The behaviours are not evolving the system productively; they are creating tensions between credentials and experience. The maladaptation this causes, produces a subset of behaviours where professionals choose to no longer study hard to stand still, and the result is that they become extinct. On this basis, they do not become extinct because their expertise and experience is no longer relevant, but rather because they no longer hold the latest professional qualification.

\section{Conclusion}

Professionalisation is often viewed as a process impacting on one whole group of the workforce and there is evidence of the ongoing professionalisation of Operating Department Practitioners and Theatre Nurses in this study. The incorporation of hospital-based training schools into higher education and the move to graduate entry for nursing suggests that the nursing profession is moving towards the final stages of this process according to Larson (1977). This evolution of the nursing profession has stimulated a similar move in the ODP profession as they compete for equal status with nursing.

However, this study also provides evidence of individual competition which is both inter- and intra-professional as some healthcare professionals with professional qualifications of a lower academic level participate in credentialised continuing professional development activities. Their activities are purposefully enacted to 
maintain their competitiveness with the new breed of graduate professional entrants, but places them only at the same point as the new breed in terms of their academic award. The metaphor of the Red Queen is used to describe this evolutionary process, where the professional development is likened to running fast to stand still. Those that fail to adapt in this way ultimately face extinction.

Although the findings from this study should be treated with caution due to the small sample size, they provide a unique insight into how some professionals are responding to the national policy change in the pre-registration preparation of health care professionals.

\section{References}

Aiken, L. H., S. P. Clarke, R. B. Cheung, D. M. Sloane, and J. H. Silber (2003) Educational Levels of Hospital Nurses and Surgical Patient Mortality. Journal of American Medical Association 290 (12) p. 1617 - 1637

Barnett, W. P., and M. T. Hansen (1997) The Red Queen in Organizational Evolution Strategic Management Journal 17 p. 139 - 157

Becker, G. S (1993) Human Capital: A Theoretical and Empirical Analysis with Special Reference to Education ( $3^{\text {rd }}$ Edition). Chicago: The University of Chicago Press

Bryman, A. (2007) The Research Question in Social Research: What is its Role? International Journal of Research Methodology, 101 p. 5 - 20

Canibano, C. and J. Potts (2016) Toward an Evolutionary Theory of Human Capital Available at

SSRN: https://ssrn.com/abstract=2802236 or http://dx.doi.org/10.2139/ssrn.2802236

College of Operating Department Practitioners (2011a) BSc (Hons) Operating Department Practice Discussion Paper. London: College of Operating Department Practitioners

College of Operating Department Practitioners (2011b) BSc (Hons) Operating Department Practice Curriculum Document. London: College of Operating Department Practitioners

Corbett, R. (2017) Human capital in the operating department: the significance of academic qualifications to the operating theatre workforce. Available from http://ethos.bl.uk/OrderDetails.do?did=2\&uin=uk.bl.ethos. 706980 
Debell, D. and K. Branson (2009) Implementing graduate entry registration for nursing in England: a scope review. Journal of Nursing Management (17) p. 550 - 558

Department of Health (2008) A High Quality Workforce: NHS Next Stage Review [Online] Available from:

www.dh.gov.uk/prod_consum_dh/groups/dh_digitalassets/@dh/@en/documents/digital asset/dh_085841.pdf [Accessed: 11th March 2012]

Department of Health (2004) The NHS Knowledge and Skills Framework (NHS KSF) and the Development Review Process. London: Department of Health Publications

Doyle, W. R. (2006) Running: Twice As Fast, Just To Keep Up Change: The Magazine of Higher Learning 38 (2) p. 57 - 58

Easton, P. (2007) Adult Education and Social Sustainability: Harnessing the 'Red Queen Effect' Convergence XL (1 - 2) p. $171-18$

Freedman, L. (2015) Strategy: A History. New York: Oxford University Press

Gorard, S. (2010) Research design as independent of methods in A. Tashakkori and C. Teddlie (Eds.) Sage Handbook of Mixed Methods in Social and Behavioral Research (2nd Edition). Los Angeles: Sage p. 237 - 251

Health and Care Professions Council (2017) Standards of education and training [Online] Available from: http://www.hcpcuk.org/assets/documents/10000BCF46345Educ-Train-SOPA5_v2.pdf [Accessed: 30 th July 2017]

Health and Care Professions Council (2016) Standards of conduct, performance and ethics [Online] Available from http://www.hcpcuk.org/assets/documents/10004EDFStandardsofconduct,performanceandethics.pdf [Accessed 15 ${ }^{\text {th }}$ April 2017]

Johnson, B. and R. Gray (2010) A History of Philosophical and Theoretical Issues for Mixed Methods Research in A. Tashakkori and C. Teddlie (Eds.) Sage Handbook of Mixed Methods in Social and Behavioral Research (2nd Edition). Los Angeles: Sage p. $69-94$

Keep, E., Mayhew, K., and Payne, J. (2006) From Skills Revolution to Productivity Miracle - Not as Easy as it Sounds? Oxford Review of Economic Policy 22 (4) p. 539 559

Larson, M. S. (1977) The Rise of Professionalism: a sociological analysis. Berkley: University of California Press

Nancarrow, S. A., and A. M. Borthwick (2005) Dynamic professional boundaries in the healthcare workforce Sociology of Health and Illness p. 897 - 919 
NHS England (2014) Five Year Forward View [Online] Available from: https://www.england.nhs.uk/wp-content/uploads/2014/10/5yfv-web.pdf [Accessed 19th August 2015]

Nursing and Midwifery Council (2015) The Code: Professional standards of practice and behaviour for nurses and midwives [Online]

http://www.nmc.org.uk/globalassets/sitedocuments/nmc-publications/revised-new-nmccode.pdf [Accessed: 19th August 2015]

Nursing and Midwifery Council (2010) Pre-registration nursing education in the UK [Online] Available from:

http://www.nmc.org.uk/globalassets/sitedocuments/standards/nmc-standards-for-preregistration-nursing-education.pdf [Accessed: 19th August 2015]

Reid, J. and K. Catchpole (2011) Patient safety: a core value of nursing - so why is achieving it so difficult? Journal of Research in Nursing 16 (3) p. $209-223$

Tashakkori, A. and C. Teddlie (2010) Putting the Human Back in "Human Research Methodology": The Researcher in Mixed Methods Research Journal of Mixed Methods Research 44 p. $271-277$

Timmons, S. (2011) Professionalisation and its discontents. Health 15 (4) p. 337 - 352

Timmons, S. and J. Tanner (2004) A disputed occupational boundary: operating theatre nurses and Operating Department Practitioners Sociology of Health \& Illness 26 (5) p. $645-666$

Torrance, H. (2012) Triangulation, Respondent Validation, and Democratic Participation in Mixed Methods Research Journal of Mixed Methods Research 6 (2) p. $111-123$

Van Valen, L. (1973) A New Evolutionary Law. Evolutionary Theory 1 p. 1 - 30

Yam, B. M. C. (2004) From vocation to profession: the quest for professionalisation of nursing. British Journal of Nursing 13 (16) p. $978-982$ 